\title{
SARAU LITERÁRIO - A INOVAÇÃO PARA UMA AVENTURA LITERÁRIA POR WEBCONFERÊNCIA
}

\author{
SÃO PAULO/SP JULHO/2018
}

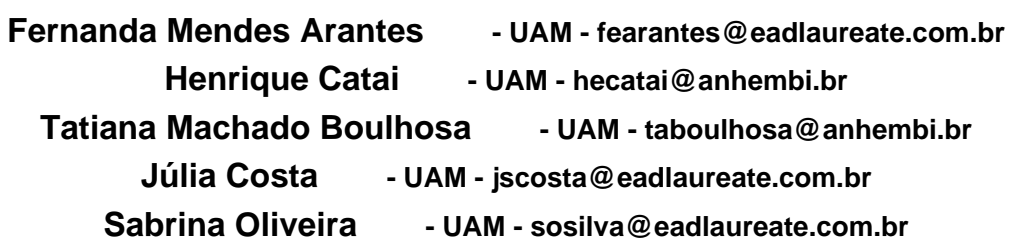

\author{
Tipo: Relato de Experiência Inovadora (EI) \\ Categoria: Métodos e Tecnologias \\ Setor Educacional: EDUCAÇÃO SUPERIOR
}

\begin{abstract}
RESUMO
Um sarau constitui um evento literário e artístico que esteve presente, principalmente, nas casas de aristocratas e intelectuais brasileiros do século XIX e XX. Atualmente, algumas cidades e grupos intelectuais tem realizados Saraus em diferentes espaços. Diante desse cenário, o curso de Letras e Pedagogia do das instituições envolvidas propôs um projeto inovador que constituía a realização de um Sarau utilizando a internet, transmitido via Blackboard Collaborate. Nosso objetivo geral focou desenvolver um projeto e executar um Sarau por meio da internet, integrando diferentes polos em uma transmissão em tempo real. Foi montado um Grupo de Trabalho que elaborou o projeto, documentos, avisos, inscrição de estudantes para apresentação. O evento ocorreu no mês de outubro nos anos de 2016 e 2017 com a participação de mais de 30 polos e de todas as instituições envolvidas no projeto. Estudantes de diferentes polos apresentaram textos em prosa e verso de autores da literatura brasileira e de produção pessoal. Concluímos que o evento, independente de alguns problemas relacionados as questões tecnológicas de acesso em tempo real, produziu resultados positivos. Destacamos a integração dos polos, o envolvimento dos estudantes nas apresentações, a participação dos docentes e tutores no desenvolvimento e nas diversas fases do projeto, finalmente, o ineditismo do evento em termos culturais e científicos.
\end{abstract}

Palavras-chave: Sarau, EaD, Literatura, Cultura; Letras; Pedagogia; Webconferência.

\section{AGRADECIMENTOS}

AGRADECEMOS A TODAS AS INSTITUIÇÕES ENVOLVIDAS. 


\section{INTRODUÇÃO}

Imagina se falássemos para as famílias nobres do Brasil, ainda colônia de Portugal: "Um dia o seu sarau será de todos e conectando diferentes locais!" Nenhuma pessoa do século XIX e início do século XX poderia pensar que em pleno século XXI um Sarau poderia unir tantas pessoas em diferentes pontos do território brasileiro e de forma sincrona.

Pois bem, foi isso que aconteceu. No dia 19 de outubro de 2016 foi realizado o primeiro Sarau via webconferência, uma inovação no âmbito do universo e produção cultural e educacional. O evento foi transmitido via Blackboard Collaborate e uniu estudantes, tutores e professores e diferentes polos que congregam as 4 instituições envolvidas. A segunda edição do evento ocorreu em 25 de outubro de 2017.

O Sarau via Webconferência foi o primeiro SARAU que teve uma transmissão e conexão com diferentes polos e em diversas localidades do Brasil.

Porém, você pode perguntar: O que é um Sarau?

A ideia de Sarau chegou em terras brasileiras com a vinda da Família Real Portuguesa (1808). Semelhante ao que acontecia na Europa, as famílias começavam a copiar e realizar encontros que juntavam música, literatura, champanhe e vinho. Essa atividade cultural cresceu no processo de urbanização das cidades brasileiras.

Em diversas cidades brasileiras, os nobres e outros grupos com poder financeiro e social organizavam tais encontros. Com a participação de piano de cauda, poetas e músicos ilustres, artistas anônimos e em busca de mecenas.

$\mathrm{Na}$ primeira metade do século $\mathrm{XX}$ os saraus continuaram ocorrendo em casas de pessoas com poder financeiro. As mudanças sociais, o surgimento do rádio e, posteriormente, da televisão, além de nova dinâmica da atividade cultural levou a um "quase" desparecimento de tal atividade cultural.

Nos últimos anos, grupos culturais, jovens universitários, músicos, poetas e escritores começaram a juntar grupos e realizar pequenos encontros.

Agora podemos encontrar diversos encontros denominados como Sarau. Além da performance literária, ocorre também performances teatrais e outras ações artísticas. No Sarau via webconferência conseguimos desenvolver todos os aspectos que envolvem 
esse tipo de evento cultural. Tivemos apresentações de poesias, contos e músicas. Foram mais de 35 polos conectados ao mesmo tempo, ouvindo e vendo as apresentações. Houve apresentação de estudantes, professores e tutores.

A plataforma tecnológica do Ensino a Distância utilizado nas IES é uma das mais desenvolvidas e criativas existentes no mercado mundial. Por meio do Blackboard Colaborate (2017), os estudantes das IES envolvidas podem se comunicar com todo 0 corpo docente e seus colegas das disciplinas em diversas localidades.

O objetivo geral desse texto reside em: Apresentar o projeto, o planejamento e a execução de um Sarau por meio da plataforma Blackboard Colaborate, integrando polos de diferentes IES presentes no território brasileiro das IES envolvidas.

Também abordarmos, paralelamente, objetivos específicos: Demonstrar a metodologia e execução do Sarau via Blackboard Colaborate como ferramenta pedagógica para o ensino e engajamento de estudantes, tutores e docentes. Além disso, reativar a cultura do Sarau como instrumento de encontro e troca de experiências sociais, culturais, afetivas e aprendizado.

\section{REFERENCIAL TEÓRICO}

A realização de um Sarau busca resgatar e adequar um evento reconhecido no meio literário e intelectual para um espaço virtual, utilizando novas tecnologias como webconferências, vídeos e inscrições virtuais. Para isto, busca relacionar o conteúdo do curso, em específico as disciplinas: Teoria da Literatura, Literatura Portuguesa, Literatura Brasileira I e II com a apresentação aqui mencionada. O professor orientador da atividade, pede, previamente que os estudantes elaborem seus materiais tendo por base os conteúdos trabalhados nestas disciplinas.

O Sarau constitui um encontro entre pessoas para conversar, dialogar, declamar poesias e prosas, cantar e tocar instrumentos musicais. De acordo com o Dicionário Contemporâneo da Língua Portuguesa de Caldas Aulete (2017), Sarau possui o seguinte significado: "1. Reunião noturna, de caráter musical ou literário: "(...) por entre as sessões de teatro, os saraus e tertúlias nas diversas casas elegantes (...)." (Ana Maria Machado, A audácia dessa mulher) 2. Concerto musical à noite [F.: Do galego serao]."

Identificamos que dentro dessa definição a visão que o Sarau constitui um evento realizado em residências e uma reunião de pessoas. A imagem de reunir pessoas em 
um determinado espaço constitui uma forma tradicional de pensar um evento.

Todavia, as mudanças advindas com o uso das tecnologias da informação permitiram que um grupo de pessoas tenha a possibilidade de criar encontros denominados virtuais, mas mantendo as características de uma comunicação verbal e não-verbal. Ferramentas como Hangouts, Skype e Blackboard Collaborate (2017) possibilitam que um grupo de pessoas em diferentes espaços geográficos possam marcar uma reunião e abordar um determinado assunto. De acordo com Daniel Araújo Castro (2017): “A Internet é uma poderosa ferramenta para juntar pessoas com interesses semelhantes, ou opiniões semelhantes. Existem experimentos promissores que colocam pessoas com diferentes visões juntas em fóruns na Internet para discutir temas específicos. Mas essas experiências raramente parecem ocorrer naturalmente, do modo que as comunidades de afinidade se desenvolvem espontaneamente. Assim, alcançar resultados em grupos díspares exige grande esforço, comprometimento e recursos. Além dos custos da tecnologia adequada, esses experimentos requerem planejamento cuidadoso e moderação consistente."

Esse cenário tem-se intensificado nos últimos anos e em situações das mais diversas, permitindo que no ambiente educacional um grande número de estudantes tenha um contato com outros grupos em diferentes localidades geográficas.

Nesse sentido, surge a ideia de desenvolver um evento que possa levar a essência do Sarau para o universo virtual, proporcionando o diálogo e aprendizado entre estudantes de diferentes regiões do território brasileiro.

Como essência definimos que a elaboração de um Sarau Virtual necessita manter características como: aspecto literário, musicalidade, comunicação e apresentação artística. Tais pilares foram contemplados no Sarau via webconferência como é possível identificar em resultados.

Além do desafio de implementar um evento como Sarau em um ambiente novo e digital, percebe-se pouca ou rara referência teórica que aborde a constituição desse tipo de evento no espaço virtual. Localizou-se trabalhos acadêmicos que abordavam o Sarau Virtual, porém não de forma síncrona. As postagens e apresentações eram realizadas pelos participantes e não havia um encontro síncrono, a exemplo do projeto de Sarau Virtual elaborado por Faria et al (2017).

Outra questão que envolve o Sarau em um ambiente acadêmico é a oportunidade de apresentar aos estudantes de Pedagogia e Letras uma atividade cultural e pedagógica, 
compartilhando sua prática e uso em futuras atuações profissionais de docência, coordenação pedagógica e gestão escolar.

Nesse caminho, identificamos que uma das formas de aprimorar o conhecimento, competências e habilidades do estudante do EaD era a criação e execução de um Sarau. O Sarau como evento funda uma perspectiva lúdica do aprendizado da literatura e da oratura. Conforme afirma Antonio Santos (2017): "A escola constitui-se para criança num novo espaço de comunicação e interrelação em que também a oralidade deverá ser revista para atender a esse novo contexto e a esses novos personagens. $A$ promoção de atividades que mostrem a leitura para a manifestação do pensamento pela oralidade em poemas, contos, causos e outros...certamente contribuirão para que as metas e objetivos ressaltados anteriormente sejam efetivados."

Trazer uma nova forma de contato com o texto literário e produção artística é uma tarefa básica do docente e das Instituições de Ensino Superior que atuam com cursos de licenciatura e Pedagogia. A participação em eventos culturais dos estudantes do ensino superior proporciona a propagação da ideia em escolas de ensino fundamental e médio, pois estes serão futuros docentes e coordenadores em escolas públicas e privadas. Além disso, o estudante de Letras e Pedagogia terá o contato e convívio com eventos culturais que promovem a literatura, música e outros movimentos artísticos.

O Brasil é um país com diversidades culturais ricas e distintas. Contudo, a necessidade do cumprimento das emantas das disciplinas podem limitar esta imensa troca cultural. Verifica-se, portanto, a necessidade e a oportunidade de criar um elo de comunicação e interação para a troca de experiências extracurriculares entre os discentes, com apoio dos docentes das disciplinas dos cursos.

\section{METODOLOGIA}

No segundo semestre de 2015 idealizou-se um projeto inicial para desenvolver um Sarau por meio de webconferência. A ideia era fazer com que estudantes do curso de Letras e Pedagogia das IES envolvidas tivessem a oportunidade de participar de um evento que é muito comum no meio cultural.

Diretor e Coordenadores apoiaram a ideia, porém no mesmo ano não foi possível sua execução por questões acadêmicas e de estrutura do evento que necessitavam ser discutidas.

No primeiro semestre de 2016 a Coordenação Geral e Diretoria solicitou aos docentes 
do curso de Letras e Pedagogia que desenvolvesse um novo projeto para iniciar e executar o evento no segundo semestre do mesmo ano. O evento teve o mesmo procedimento em sua segunda edição, no ano de 2017.

A primeira ação, corresponde o coordenador geral criar um Grupo de Trabalho (GT) para organização do Sarau. O GT do Sarau elabora um Project que apresenta as linhas do Evento.

São realizadas reuniões entre os integrantes do GT e organizado o processo de divulgação, inscrição e participação dos estudantes no Evento.

Sequencialmente, é decidido que os estudantes que participariam do evento devem pertencer aos cursos de Letras e Pedagogia das IES envolvidas. Os estudantes de outros cursos comparecem no polo e são convidados para assistir.

Nos meses de agosto, setembro e outubro são enviados avisos para os coordenadores dos referidos cursos participantes e das 4 IES. Os avisos tem como objetivo divulgar o evento, apresentar o manual para participação, como fazer a inscrição e o link de inscrição.

O GT do Sarau utiliza um sistema do google para fazer inscrição. Nele, o estudante de Letras e Pedagogia realiza sua inscrição e apresenta dados necessários para sua participação.

$\mathrm{Na}$ primeira semana de outubro fechamos as inscrições das pessoas que fazem apresentação no Sarau, sequencialmente, são enviados e-mails para confirmar a apresentação.

$\mathrm{Na}$ mesma semana inicia-se o envio de avisos (via disciplinas) para convidar os estudantes, não inscritos para apresentação, a assistirem os colegas no dia do evento

São criados dois links (apresentação e de ouvinte) por meio de ferramentas digitais e gratuitas como Sympla (2017), google Forms (2017), google Docs (2017).

O procedimento e atuação para uma segunda edição do evento em 2017 seguiu a metodologia solidificada e desenvolvida na primeira edição do evento.

\section{RESULTADOS}


No dia 19 de outubro de 2016 e 25 de outubro de 2017a base do evento foi em uma sala das IES envolvidas. Foram utilizados notebooks e caixa de som.

Nas duas edições o evento teve início as $19 \mathrm{~h}$ e, inicialmente, houve bastante dificuldade de conexão com os polos. Não ouvíamos os polos e também não havia imagem dos polos participantes.

Abrimos a fala e imagem para todos, porém depois fechamos. Finalmente, chegamos a conclusão que seria melhor abrir o som e imagem de todos. No decorrer do processo começamos a pedir para quem estivesse ouvindo que respondesse. Assim, iniciamos a apresentação.

Os professores e coordenadores das IES envolvidas abriram o evento. Em seguida, iniciamos a apresentação dos polos. As imagens foram publicadas pelos coordenadores dos cursos de Letras e Pedagogia. Houve também uma gravação de trechos publicadas na rede social Facebook.

Os tutores e professores das IES envolvidas fizeram apresentação de textos literários. O evento, nas duas edições (2016 e 2017) teve seu encerramento as $22 \mathrm{~h}$.

Houve presença de estudantes nos polos convidados como podem ser vistas na gravação da web e nos dados apresentados pelos polos. Tal material fica disponível em um link para ser postado na comunidade do curso e nas disciplinas das IES envolvidas.

Em sequência solicitamos aos polos enviar a quantidade de estudantes que estiveram no dia em seus respectivos espaços. Pedimos também que respondessem uma pesquisa de satisfação com o objetivo de iniciarmos uma avaliação para os próximos eventos, além de termos conhecimento da quantidade de ouvintes, dados que somente os polos participantes podem nos fornecer.

\section{CONSIDERAÇÕES FINAIS}

Nas duas edições realizadas o evento, de uma maneira geral, foi bem-sucedido em termos de resultado e objetivo central. Tivemos um engajamento dos estudantes de várias IES e verificamos que é realmente possível executar um evento deste porte, no âmbito nacional, dentro da estrutura tecnológica presente nas IES envolvidas.

Realizamos em 2017 uma segunda edição do evento, com um número maior de polos e estudantes das IES envolvidas. 
Identificamos que, para os próximos eventos, seria importante um controle e orientação maior em relação aos polos. Alguns estudantes reclamaram pelo fato de comparecerem ao local e ninguém estar capacitado ou informado sobre o evento, apesar da equipe do Sarau ter enviado comunicados, manuais e instruções para coordenação pedagógica de polos. Este último ficou responsável por esta intermediação entre os organizadores e os polos.

Para os próximos eventos também podemos considerar um número maior de inscritos, já que podemos levar em conta que somente $32 \%$ dos mesmos compareceram. O maior empecilho para efetivação do evento está no acesso a internet, pois a problemas de conexão em todo o território brasileiro.

Por fim, consideramos que o a periodicidade do Sarau ideal deverá ser 1 vez ao ano, pois permite a sua organização e planejamento de forma equilibrada e atendendo ao sucesso do evento. O Sarau via webconferência constitui um exemplo singular de inovação que possibilita trazer ao estudante de diferentes regiões do Brasil o conhecimento e potencial de uma atividade cultural.

\section{Referências:}

BLACKBOARD. Blackboard Collaborate ${ }^{\mathrm{TM}}$ : Uma experiência colaborativa que envolve a todos, a todo o momento e em toda a parte. Disponível em: http://blackboard.grupoa.com.br/plataformas/blackboard-collaborate/\#video1-modal. Acesso em 20 de jan. de 2017.

CALDAS AULETE, Francisco Júlio. Dicionário contemporâneo da língua portuguesa. 4.ed. Rio de Janeiro: Delta, 2015. Disponível em: http://www.aulete.com.br/sarau Acesso em 22 de fev. 2017.

CASTRO, Daniel Araújo. Os espaços virtuais de Participação da Sociedade como parte da estratégia de governo eletrônico em Minas Gerais. III Congresso Consad de Gestão Pública. Disponível: em: http://www.escoladegestao.pr.gov.br/arquivos/File/Material_\%20CONSAD/paineis_III_co ngresso_consad/painel_17/os_espacos_virtuais_de participacao_da_sociedade_como parte_da_estrategia_de_governo_eletronico_em_minas_gerais.pdf Acesso em 22 de fev. 2017.

FARIA, Daniele Ribeiro de Faria; OLIVEIRA, Nivaldo Oliveira; VIANA, Lenir de Castro; KLOSS, Claudio Fabiano; AZEVEDO, Maria Lourdes Ramos. Sarau Virtual: 
reinventando a prática de partilhar poemas e crônicas. Disponivel em: https://portal.febab.org.br/anais/article/view/1359. Acesso em 26 de fev. 2017.

SANTOS, Antonio Luceni. A presença de Saraus de Poesia na Rede Municipal de Enisno de Araçatuva como forma de resgate da oralidade literária. Disponível em http://e books.pucrs.br/edipucrs/anais/IICILLIJ/7/APRESENCADESARAUSDEPOESIANAREDE MUNICIPALDEENSINODEARACATUBACOMOFORMADERESGATEDA.pdf . Acesso em 25 de fev. 2017. 